\title{
Statistical characteristics of the total ion density in the topside ionosphere during the period 1996-2004 using empirical orthogonal function (EOF) analysis
}

\author{
B. Zhao ${ }^{1,2,3}$, W. Wan ${ }^{1}$, L. Liu ${ }^{1}$, X. Yue ${ }^{1,2,3}$, and S. Venkatraman ${ }^{4}$ \\ ${ }^{1}$ Institute of Geology and Geophysics, Chinese Academy of Sciences, Beijing 100029, China \\ ${ }^{2}$ Wuhan Institute of Physics and Mathematics, CAS, Wuhan 430071, China \\ ${ }^{3}$ Graduate School of Chinese Academy of Sciences, Beijing, China \\ ${ }^{4}$ William B. Hanson Center for Space Sciences, University of Texas at Dallas, Richardson, USA
}

Received: 6 April 2005 - Revised: 28 October 2005 - Accepted: 21 November 2005 - Published: 23 December 2005

\begin{abstract}
We have applied the empirical orthogonal function (EOF) analysis to examine the climatology of the total ion density $N i$ at $840 \mathrm{~km}$ during the period 1996-2004, obtained from the Defense Meteorological Satellite Program (DMSP) spacecraft. The data set for each of the local time (09:30 LT and 21:30 LT) is decomposed into a time mean plus the sum of EOF bases $E_{i}$ of space, multiplied by time-varying EOF coefficients $A_{i}$. Physical explanations are made on the first three EOFs, which together can capture more than $95 \%$ of the total variance of the original data set. Results show that the dominant mode that controls the $\mathrm{Ni}$ variability is the solar EUV flux, which is consistent with the results of Rich et al. (2003). The second EOF, associated with the solar declination, presents an annual (summer to winter) asymmetry that is caused by the transequatorial winds. The semiannual variation that appears in the third EOF for the evening sector is interpreted as both the effects of the equatorial electric fields and the wind patterns. Both the annual and semiannual variations are modulated by the solar flux, which has a close relationship with the $\mathrm{O}^{+}$composition. The quick convergence of the EOF expansion makes it very convenient to construct an empirical model for the original data set. The modeled results show that the accuracy of the prediction depends mainly on the first principal component which has a close relationship with the solar EUV flux.
\end{abstract}

Keywords. Ionosphere (Equatorial ionosphere; Modeling and forecasting; Solar radiation and cosmic ray effects)

\section{Introduction}

Besides the usual diurnal variation, periodic trends are often observed in the ionospheric parameters. Extensive studies have been carried out on the annual, seasonal and semiannual

Correspondence to: W. Wan

(wanw@mail.igcas.ac.cn) anomalies/variations of the ionosphere by using $\mathrm{F}_{2}$-layer peak electron content $(\mathrm{Nm} \mathrm{F} 2)$ and total electron content (TEC) (e.g. Yonezawa, 1971; Torr and Torr, 1973; Titheridge and Buonsanto, 1983; Millward et al., 1996; Balan et al., 2000; Mikhailov et al., 2000; Zou et al., 2000; Rishbeth et al., 2000; Chen et al., 2002; Unnikrishnan et al., 2002; Ma et al., 2003; Yu et al., 2004). Evidence has shown that these cyclic variations in the ionosphere have altitudinal dependence. The plasma density at varied altitudes behaves in a somewhat different way. For example, Su et al. (1998) have compared the electron densities in the $600-\mathrm{km}$ ionosphere during the June and December solstices, as measured by the Hinotori satellite. They found the annual anomaly to be very large, which is contrary to the small annual component in the F-region (Torr and Torr, 1973). Observations also showed strong seasonal variations during solstices, with the electron density at $600-\mathrm{km}$ in altitude being higher in the summer hemisphere than in the winter hemisphere, contrary to the behavior in $N m$ F2. Balan et al. (1998) and Bailey et al. (2000) found that the strength of equinoctial asymmetry, where higher electron density occurrs during March equinox in the Northern Hemisphere and during September equinox in the Southern Hemisphere, increases with increasing altitude. More recently, by using the data set of the Defense Meteorological Satellite Program (DMSP) that covers the 11-year solar cycle, Rich et al. (2003) revealed that plasma density in the mid-latitude to low-latitude ionosphere at $840 \mathrm{~km}$ varies with a period of 27 days, synchronized with the same variation in the $F_{10.7}$ index. However, ionospheric parameters, such as TEC, which are strongly influenced by the ionosphere around the F2 peak region, do not show a clear 27-day variation. These authors suggested that there is a 27-day cycle in both the ionization rates and heat production in the lower ionosphere, but the signatures in the plasma parameters are obscured by plasma dynamics which do not affect the topside ionosphere. Therefore, the plasma density at varied altitudes behaves in a somewhat different way. 


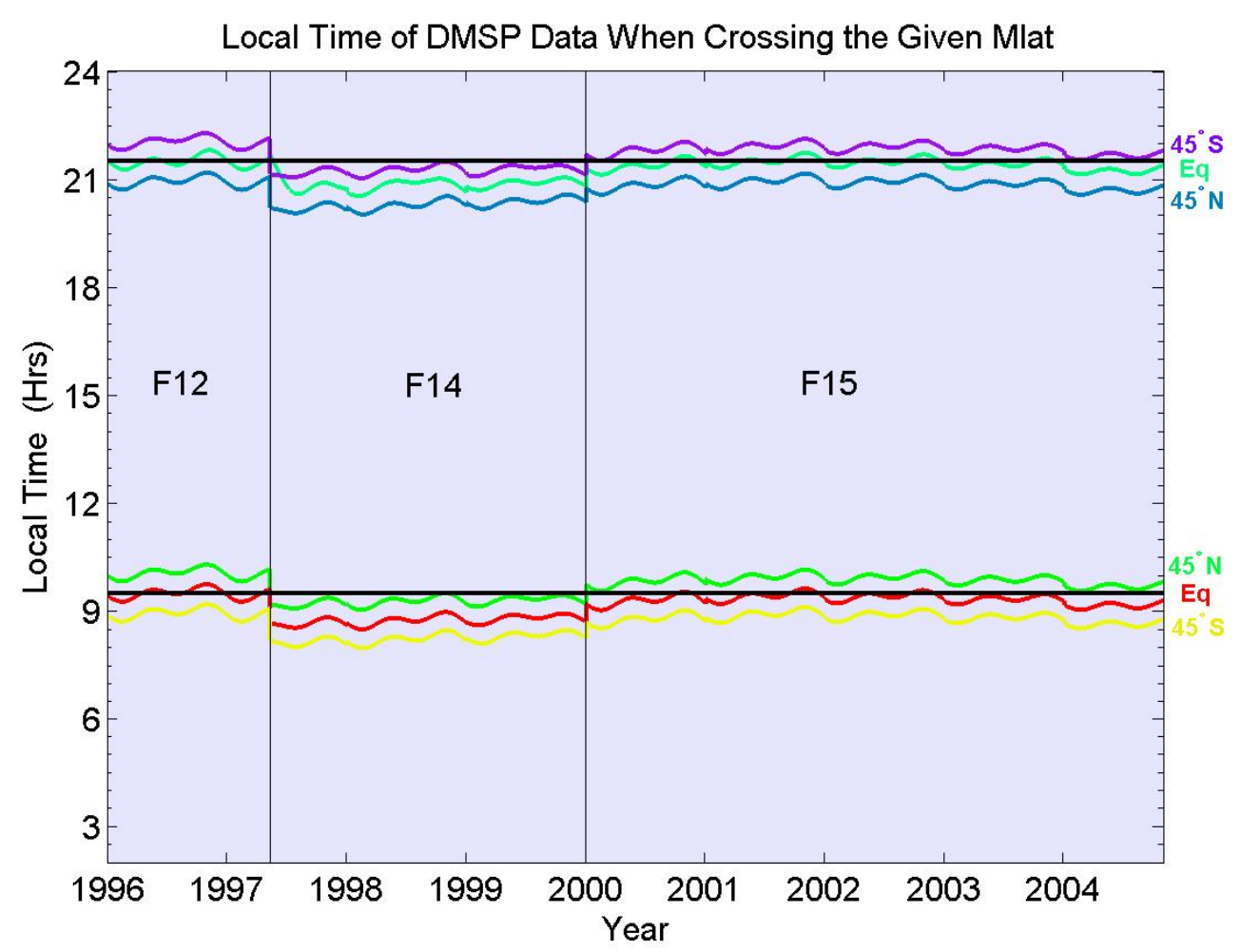

Fig. 1. Local time of DMSP satellites being used in the paper when crossing the given geomagnetic latitudes. Horizontal black lines denote 09:30 LT and 21:30 LT, respectively.

To explore how the topside ionosphere varies differently from the bottom and peak regions, we expand the work of Rich et al. (2003) by parameterizing the latitude distribution of plasma density in the topside ionosphere over 9 years by using the empirical orthogonal function (EOF) method. After a brief introduction to the data resources and method, the EOF analysis is used on the data. Then we inspect the different order EOF components to reveal the possible physical meaning. Finally, a statistical model based on the first three EOF components and their associated coefficients is established for prediction. After comparing the predicted results with the original data set, we found that the predictions can well reproduce the 27-day seasonal and semiannual variations. Through error analysis, we found that the accuracy of the prediction depends mainly on the first principal component which has a close relationship with the solar flux.

\section{Data description}

DMSP spacecraft are launched in a near polar, Sunsynchronous orbit, at a constant geocentric altitude of $\sim 840 \mathrm{~km}$. Since 1987, a series of DMSP spacecraft, named with the letter $\mathrm{F}$ and the flight number, have been sent to their designated orbits. They carried an instrumentation package to monitor the behavior of thermal plasma in the topside ionosphere. The "Special Sensor-Ions, Electrons and Scintillation" (SSIES) package on aboard the DMSP satellites consists of four instruments: a Langmuir Probe (LP), a Retarding Potential Analyzer (RPA), an Ion Drift Meter (IDM) and a Scintillation Meter (SM). This instrument package has been described by Rich (1994), Greenspan et al. (1994), and Rich and Hairston (1994). In this study, the plasma density $(\mathrm{Ni})$ is obtained from the SM instrument. The fractional composition of the plasma (percentages of $\mathrm{H}^{+}, \mathrm{He}^{+}$, and $\mathrm{O}^{+}$) is derived from the RPA data. All these data are provided with a 4-s resolution at the University of Texas, Dallas web site.

The data set used in this paper is provided by the F12, F14 and F15 satellites, covering the period from 1 January 1996 to 31 October 2004. The satellite orbits are approximately in the 09:30/21:30 LT orbital plane. The orbit period is around $101 \mathrm{~min}$, giving just over 14 orbits a day, each separated in longitude by around $25^{\circ}$ (Venkatraman and Heelis, 1999a). The overlapped operational time of these three spacecraft ensures the data's integrity. Figure 1 shows the local time distribution of the DMSP satellites being used in the paper when crossing the given geomagnetic latitudes. As seen from Fig. 1, the spacecraft are not exactly Sun-synchronous. There is a difference of almost an hour of local time between the mid-latitude Northern Hemisphere data and the mid-latitude Southern Hemisphere data. The combination is reasonable if we consider that the topside ionosphere changes are not dramatically near the noon sector or $1-2 \mathrm{~h}$ after sunset (MacPherson et al., 1998). The nearly constant local time of DMSP orbital planes makes their ionospheric measurements 

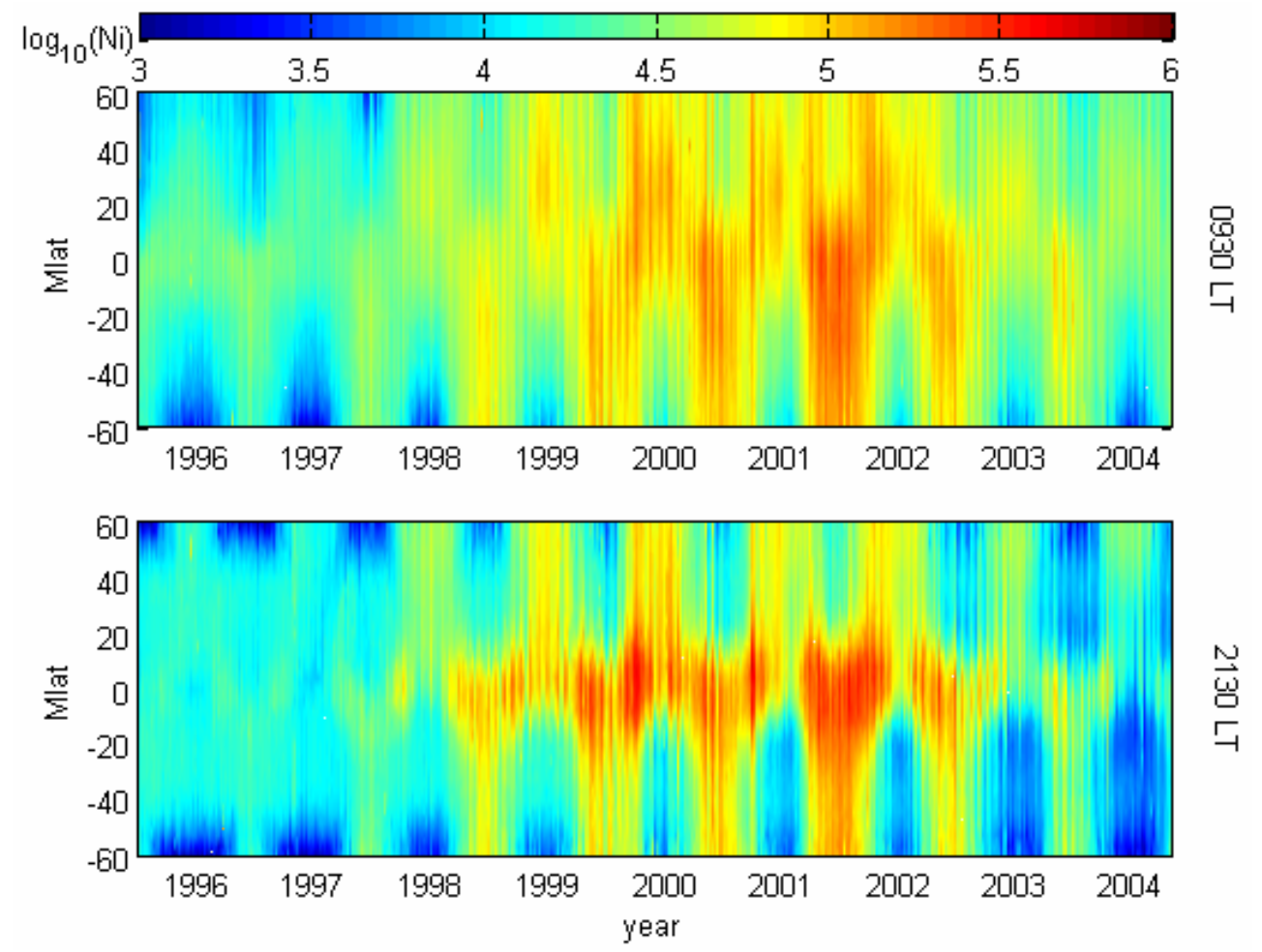

Fig. 2. Ion density distribution at magnetic latitudes $-60^{\circ} \sim 60^{\circ}$ for the period 1996-2004 at 09:30 LT and 21:30 LT.

unique for each spacecraft. Time series from any one set of the DMSP data are unaffected by local time variations (especially at low and equatorial latitudes) which can dramatically affect plasma characteristics. This constancy in LT allows other drivers of the plasma characteristics to be more noticeable. The plasma density at 09:30 LT and 21:30 LT each day was derived from the average value of total day crossings and night crossings on that day. In order to emphasize large-scale latitudinal variations in the equatorial and middle latitudes, the data are initially averaged over 4-deg intervals at each degree of latitude between $\pm 60^{\circ}$ magnetic latitude. Any irregularities in the data set are neglected before taking the average. This allows small-scale irregularities produced by slightly different characteristics in the instrument to be removed. Figure 2 shows the plasma density $(\mathrm{Ni})$ variation during 1996-2004 versus universal time and geomagnetic latitude at 09:30 and 21:30 LT. As can be seen from Fig. 2, Ni increases rapidly from solar minimum to solar maximum. For both Northern and Southern Hemispheres, the plasma density presents a clear annual variation. The nighttime plasma density is obviously lower at all latitudes during solar minimum compared with that during the daytime. In the low-latitude and equatorial areas, the nighttime plasma density is even higher than the daytime density during solar maximum, due to the post-sunset uplift of the equatorial ionosphere (Fejer et al., 1999).

The observed radio flux at a wavelength of $10.7 \mathrm{~cm}\left(F_{10.7}\right)$ at local noon is used as a standard proxy for the flux of EUV radiation reaching the Earth. In this paper, we adopt the adjusted flux to remove the $7 \%$ annual variation that arises from the changing Sun-Earth distance with respect to the observed value.

\section{Empirical orthogonal functions analysis}

Commonly, a technique in deriving the principle component of the periodic variation in ionospheric parameters is the Fourier analysis method, by which the predominant first harmonic and other high-order harmonics are obtained. Since the basic function set used in the Fourier analysis is artificially designed as sine and cosine functions, Fourier analysis is more or less mathematical. Empirical orthogonal function (EOF) analysis is the decomposition of the data set on a base of orthonormal functions which are directly determined by the data set itself (Xu and Kamide, 2004). The main idea of using EOF is to suggest a linear transformation of the original data, producing a new set of orthogonal functions, which simplifies and excludes redundant information. The fundamental orthogonal basic functions are naturally obtained during the calculation procedure. Therefore, they possess the inherent characteristics of the original data, and the eigen series converges much more quickly. EOF analysis has been used extensively to represent meteorological and climatology data since the 1950's (see Storch and Zwiers, 2002, and reference therein). It has also been used for empirical ionospheric modeling. Daniell et al. (1995) applied EOFs to present the altitude profiles of ion concentration in their parameterized 
Table 1. Summary of variances at 09:30 LT captured from the DMSP data set by the first five Empirical Orthogonal Functions (EOFs).

\begin{tabular}{lcc}
\hline EOF & \%Variance & Cumulative \%Variance \\
\hline 1 & 81.2951 & 81.2951 \\
2 & 16.3589 & 97.6539 \\
3 & 1.4035 & 99.0575 \\
4 & 0.3066 & 99.3641 \\
5 & 0.2425 & 99.6067 \\
\hline
\end{tabular}

Table 2. The same as Table 1, but at 21:30 LT.

\begin{tabular}{lcc}
\hline EOF & \% Variance & Cumulative \%Variance \\
\hline 1 & 78.6840 & 78.6840 \\
2 & 17.3711 & 96.0551 \\
3 & 1.8116 & 97.8667 \\
4 & 0.6461 & 98.5127 \\
5 & 0.3708 & 98.8836 \\
\hline
\end{tabular}

model of the ionosphere. Generally, it is possible to represent any 2-D data set (i.e. data in space and time) as a time mean plus the sum of orthogonal functions of space multiplied by time-varying coefficients. Therefore, the expansion of $N i$, not the $\log _{10}(N i)$, can be represented as

$$
\begin{gathered}
N i(d, m)=\overline{N i}(m)+\sum_{k=1}^{M} A_{k}(d) \times E_{k}(m) \\
d=1,2, \cdots, D ; \quad D=3227 \\
m=1,2, \cdots, M ; \quad M=31
\end{gathered}
$$

where $d$ is the number of the day which starts from 1 January 1996 and ends on 31 October 2004; $m$ is the number of points in each geomagnetic latitude profile; $\overline{N i}$ is the time mean of the $N i$ distribution; the coefficients $A_{k}$ are usually referred to as the principal components, and the base functions $E_{k}$ are empirical orthogonal functions (EOFs). $E_{k}$ are functions of geomagnetic latitude and represent the latitude variability in the data set, while the principal components describe how this latitude feature varies in time. The calculation of the EOF bases and their coefficients is mainly based on the eigenvalue/eigenvector problem which can be referred to in the work of Daniell et al. (1995).

Typically, the EOFs are arranged in order of the decreasing variance they can capture in the original data set. Tables 1 and 2 list the percentage variance captured by each of the five EOFs derived from the DMSP data set over 9 years at 09:30 LT and 21:30 LT, respectively. As can be seen from Table 1, covariance contributions of the first three components $\left(A_{1} * E_{1}, A_{2} * E_{2}\right.$ and $\left.A_{3} * E_{3}\right)$ are $81.2951 \%, 16.3589 \%$, and $1.4035 \%$, respectively. Altogether, they are able to explain $99.0575 \%$ of the data set total variance, leaving only $0.9425 \%$ unexplained. This manifests one of the important advantages of the EOF analysis, in that only a few EOF components are required to represent most of the variability of the data set. This is also illustrated in Table 2: the first three EOFs are capable of explaining $78.6840 \%, 17.3711 \%$, and $1.8116 \%$ of the total variance, respectively.

The mean and first three EOFs are shown in Fig. 3, while the first three principal components coefficients are shown in Fig. 4. The normal convention of presenting EOFs in terms of physical units has been followed. Both EOFs and principal components have been scaled, so that the variances of the principal component time series are unity. Before we present our results from DMSP data, we briefly describe the topside ionospheric physics which is relevant to our data interpretation.

The topside ionosphere is mainly composed of three ions $\mathrm{O}^{+}, \mathrm{H}^{+}$and $\mathrm{He}^{+}$, of which the abundances are dominated by transport and chemical processes. Typically, $\mathrm{O}^{+}$and $\mathrm{He}^{+}$ each are produced by photoionization of neutral oxygen and helium, and lost by recombination with $\mathrm{O}_{2}$ and $\mathrm{N}_{2} . \mathrm{H}^{+}$is generated and decays through the reversible charge exchange reaction $\mathrm{H}^{+}+\mathrm{O} \leftrightarrow \mathrm{O}^{+}+\mathrm{H}$. Under a diffusive equilibrium condition, the topside ionosphere becomes stratified as the helium layer is constrained between the $\mathrm{O}^{+}$layer at the bottom and the $\mathrm{H}^{+}$layer on top, due to different ion masses (González et al., 2004). The ion components in the topside ionosphere are known to vary with location, local time, season, solar cycle, and magnetic activity (e.g. Watt, 1965; Brace et al., 1968; Taylor, 1970; Moffett and Hanson, 1973; Titheridge, 1976; Miyazaki, 1979; Kutiev et al., 1980; Heelis et al., 1990; González et al., 1992, 2004; West and Heelis, 1996; West et al., 1997; MacPherson et al., 1998). This variability is also illustrated in Fig. 5. During solar minimum in 1996, at 09:30 LT, $\mathrm{H}^{+}$and $\mathrm{He}^{+}$predominated the topside ionosphere at the satellite altitude of $840 \mathrm{~km}$, between $\pm 50^{\circ}$. At equinox for both hemispheres and during summer solstice between $20^{\circ}-40^{\circ}$ in the summer hemisphere, $\mathrm{He}^{+}$ exceeds $\mathrm{H}^{+}$to become the major ion in the topside ionosphere. The equinoctial symmetric and solstitial asymmetric distribution of $\mathrm{He}^{+}$should be a result of a combination of the $\boldsymbol{E} \times \boldsymbol{B}$-fountain effect and transequatorial wind (Moffett and Hanson, 1973; Heelis et al., 1990). At 21:30 LT, an $\mathrm{He}^{+}$production source disappears and downward transport of $\mathrm{H}^{+}$is shown to prevail at the satellite altitude. At 09:30 LT and 21:30 LT, beyond $\pm 40^{\circ}$, the ratio of $\mathrm{O}^{+}$begins to increase with increasing latitude and is most obvious in the summer hemisphere. This may be due to the rapidly increasing flux tube volume with increasing latitude. The magnetic flux tubes contain sufficient $\mathrm{H}^{+}$from the protonosphere that downward diffusion and charge exchange are able to maintain the $\mathrm{O}^{+}$concentration. The large dip angle at these latitudes also means that a summer to winter component of the F-region neutral wind can support $\mathrm{O}^{+}$and the decrease in its flow to lower altitudes, where the decay rate is high. During solar maximum in $2000, \mathrm{O}^{+}$is shown to be predominant in the total ion concentration because of the expansion of the Fregion. Solstitial hemispheric asymmetries in ion concentration, due to modulation of the F-peak height, are also clearly seen, with a minimum in the $\mathrm{O}^{+} / \mathrm{He}^{+}$and $\mathrm{O}^{+} / \mathrm{H}^{+}$ratios at about $30^{\circ}$ in the winter hemisphere at 09:30 LT and 21:30 LT. 

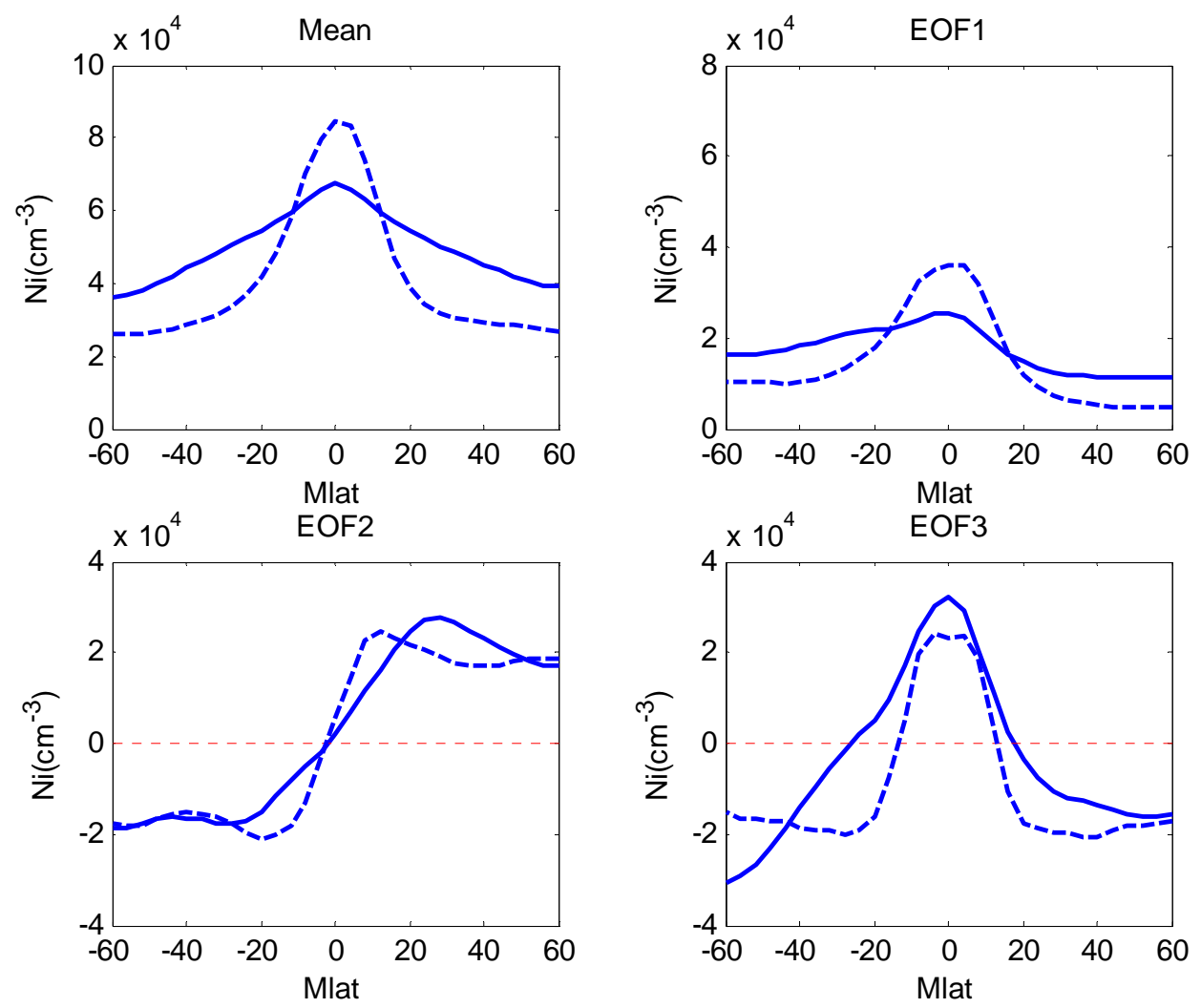

Fig. 3. Mean ion density and first three empirical orthogonal functions derived from the DMSP data set. Solid line represents the value at 09:30 LT and dashed lines represent that at 21:30 LT.

During both solar minimum and maximum for 09:30 LT, the $\left[\mathrm{H}^{+}\right] /\left[\mathrm{He}^{+}\right]$ratio presents the same seasonal variation as the $\left[\mathrm{He}^{+}\right] /\left[\mathrm{O}^{+}\right]$ratio at $\pm 30^{\circ}-40^{\circ}$, suggesting the different role $\mathrm{He}^{+}$plays during different solar levels.

The plasma distribution in the equatorial and mid-latitude ionosphere is subject to a number of transport processes involving thermospheric neutral winds, diffusion along the magnetic field line, and $\boldsymbol{E} \times \boldsymbol{B}$ drifts (e.g. Heelis et al., 1978; Heelis and Hanson, 1980; Murphy et al., 1984; Greenspan et al., 1994; Venkatraman and Heelis, 1999a, 1999b, 2000). During the daytime, the photoionization of atomic oxygen in the F-region creates an upward pressure gradient force in the topside ionosphere. As a result, the newly-created $\mathrm{O}^{+}$diffuses upward along the magnetic field lines. The plasma also undergoes an upward $\boldsymbol{E} \times \boldsymbol{B}$ drift motion during the daytime. The upward diffusion and $\boldsymbol{E} \times \boldsymbol{B}$ drift of plasma during the daytime make the oxygen ion the dominant species at the altitude of the DMSP satellites $(840 \mathrm{~km})$. At night, the rapid recombination of the ion species in the lower ionosphere decreases the upward diffusion of the topside plasma along the field line. The plasma also undergoes a downward $\boldsymbol{E} \times \boldsymbol{B}$ drift at night, except right after sunset when a pre-reversal enhancement occurs (Fejer, 1991). As a result, the $\mathrm{H}^{+}$population increases at nighttime in the topside ionosphere. Along with diffusion and $\boldsymbol{E} \times \boldsymbol{B}$ drift, the neutral wind motions that vary with season and local time can significantly modify the ionospheric dynamics and composition. Using DMSP F10 data West and Heelis (1996) observed substantial longitude variations of the $\mathrm{O}^{+} / \mathrm{H}^{+}$composition in dip latitudes $40^{\circ} \sim 40^{\circ}$ at different local times and seasons. The longitudinal variations of the ion composition at the height of the satellite were attributed to the modulation of the F-layer height by the neutral winds. Venkatraman and Heelis (2000) used DMSP F10 measurements and found that the field-aligned plasma flows are maximized in regions where the effects of the F-region neutral meridional and zonal winds maximize. Both studies emphasize neutral winds as a main driver of interhemispheric plasma transport in the topside ionosphere.

Figure 3 shows that the mean $N i$ at 09:30 LT (solid line) presents a dome-like distribution with maximum concentration located on the magnetic equator, which is in agreement with the past observations (e.g. Brace et al., 1967, 1968; Reddy et al., 1967). The configuration is mainly affected by geomagnetism and solar control (Chandra and Rangaswamy, 1967). In the topside ionosphere, except for the downward flux from the protonosphere, $\mathrm{H}^{+}$is mainly obtained through the charge exchange between $\mathrm{O}^{+}$and hydrogen; $\mathrm{O}^{+}$and $\mathrm{He}^{+}$ are produced by photoionization, and their production rate is proportional to the cosine of the solar zenith angle $\cos \chi$. So $N i$ is closely related to the distribution of $\cos \chi$, which is defined as:

$\cos \chi=\sin \theta \sin \delta+\cos \theta \cos \delta \cos \lambda$, 

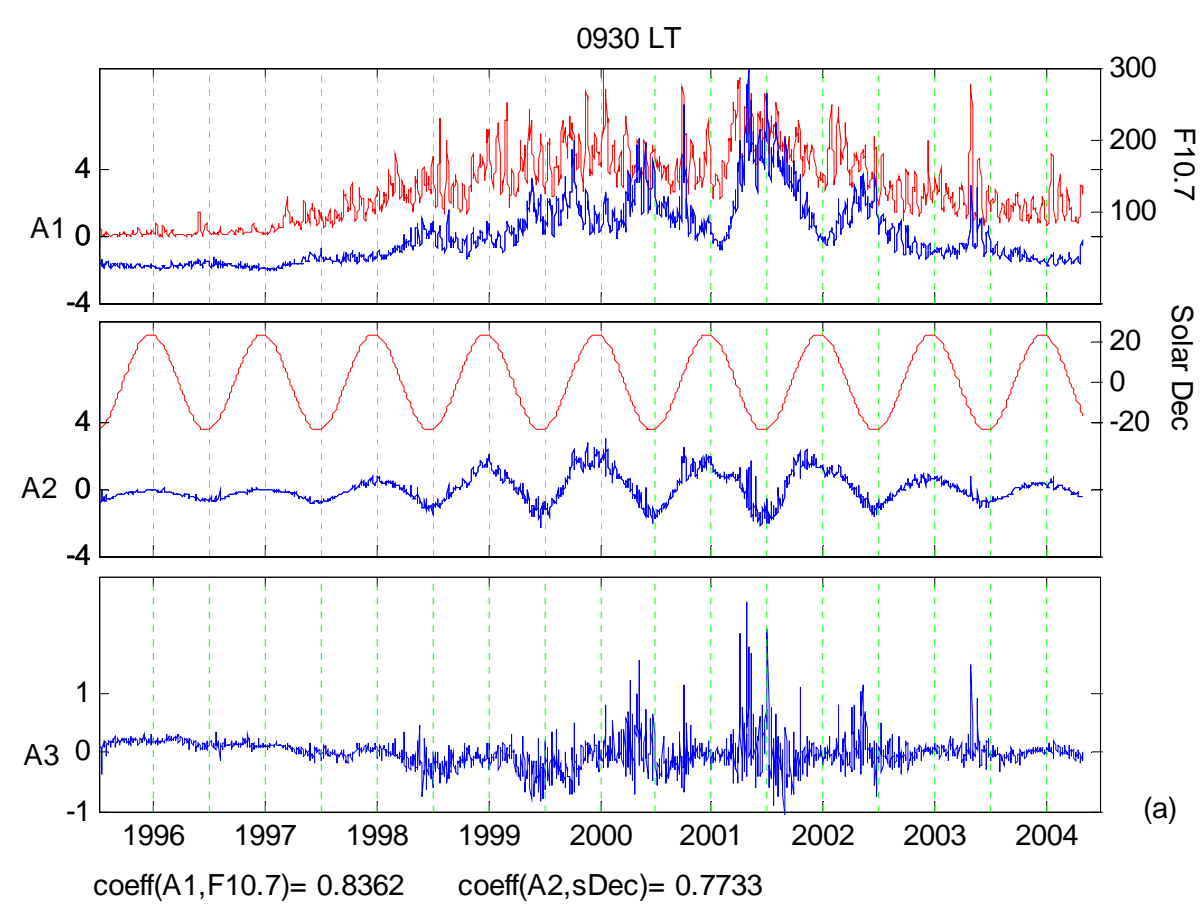

(a)

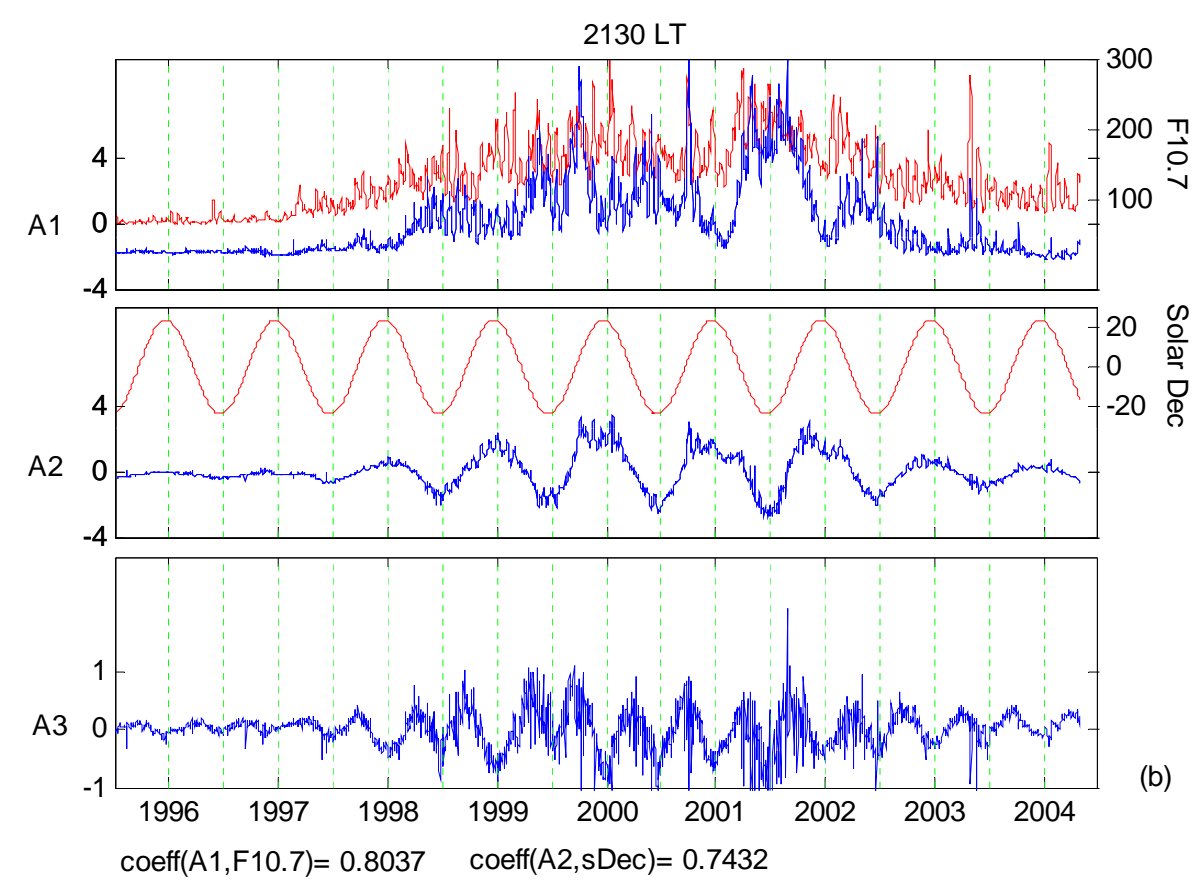

Fig. 4. Time variation in first three principal components marked by blue lines and axes on the left-hand side of the figures. Associated geophysical parameters $\left(F_{10.7}\right.$, and solar declination) are shown as red lines with values according to axes on the right-hand side of the figures. The upper panel (a) represents those of 09:30 LT and (b) denotes those of 21:30 LT.

where $\theta$ is the geographic latitude, $\delta$ is the solar declination and $\lambda$ is the solar hour angle. The statistical mean value of $\cos \chi$ is shown with a maximum at the geographic equator and depresses steadily on either side. However, the geomagnetic symmetry suggests that the magnetic control of the ion transport process is more important than the solar zenith angle control of the production processes. The maximum in $\mathrm{Ni}$ at the magnetic equator is most probably due to a field-aligned upward diffusion of electrons and ions in response to the daytime heating of the ambient electrons by escaping photoelectrons or under the influence of the electric field force (Hanson, 1963). By assuming the predominant diffusive equilibrium in the topside ionosphere, Brace et al. (1967) and Mayr et al. (1967) revealed that the latitudinal 

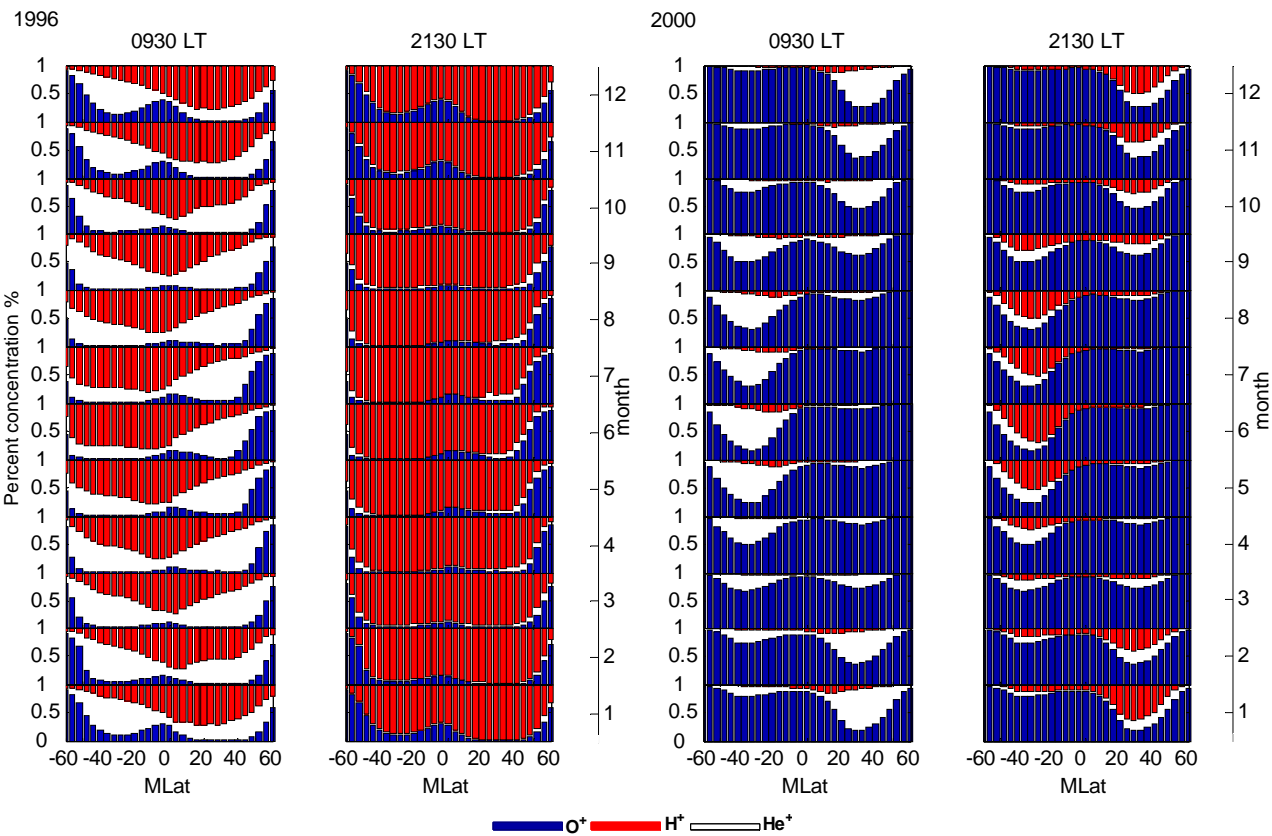

Fig. 5. Percent ion composition of the $\mathrm{O}^{+}, \mathrm{H}^{+}$, and $\mathrm{He}^{+}$at 09:30 LT and 21:30 LT for the solar minimum 1996 and maximum 2000 .

variations of temperature and density were found to be mutually self-consistent at the equator, and their results showed that the temperature minimum observed there during the daytime contributes to the equatorial density maximum. The mean $N i$ at 21:30 LT (dashed line) shows a narrow, large increase at the magnetic equator which is higher than that at 09:30 LT. The result is different from the observations of Brace et al. (1967) and Reddy et al. (1967), which showed a trough at the equator and two humps on its flanks between 00:00-03:00 LT. The inconsistency could be explained by the local time variation. Since 21:30 LT is about an hour after post-sunset, the effect of the pre-reversal enhancement of the eastward electric field still remains. The plasma in the F-region will be elevated to higher altitudes and will diffuse down along the magnetic field lines from the equator to low latitudes. Because the magnetic field line at the equator is parallel to the ground, the diffusion is slower than at other latitudes, resulting in a net increase at the equator.

The first EOF, whose covariance contribution is $81.2951 \%$ at $09: 30 \mathrm{LT}$ and $78.6840 \%$ at $21: 30 \mathrm{LT}$, appears to be associated with an enhancement in the mean value $\bar{N} i$ at all latitudes. Its corresponding principal component $A_{1}$ follows the same variability as the solar flux $F_{10.7}$ index, as illustrated in the upper panel of Figs. $4 \mathrm{a}, \mathrm{b}$. The correlation coefficient is 0.8362 for the daytime and 0.8037 for the night. Both results indicate that the topside ionosphere variation is mainly driven by the solar EUV flux, which is consistent with the conclusion of Rich et al. (2003). When solar activity becomes more active, the daytime value of the production rate increases rapidly because the flux of ionizing radiation and concentration of the atomic oxygen both increase. Enhanced ionization in the F-region contributes to the lifting of the transition height. This will increase $\mathrm{O}^{+}$(Fig. 5) and total ion concentration $N i$ at a fixed high altitude. In addition, the pre-reversal enhancement of the upward drift shown by Fejer et al. $(1981,1991)$ increases significantly with solar flux at the equator. This may also contribute to the enhanced $\mathrm{Ni}$ at 21:30 LT in the equatorial region.

Besides the enhancement at all latitudes, there is another feature we should examine. A slight asymmetry is present in the first EOF: $N i$ is higher in the Southern Hemisphere than in the Northern Hemisphere. This phenomenon is associated with the annual variation, as reported by $\mathrm{Su}$ et al. (1998), which will be discussed in the following section.

The second EOF pattern shows an obvious summer to winter (north to south) asymmetry with respect to the magnetic equator. Inspection of the corresponding principal component suggests that it represents a seasonal variation that follows the solar declination angle, as seen in Fig. 4. The correlation coefficient is 0.7733 at 09:30 LT data and 0.7432 at 21:30 LT data. Furthermore, the seasonal variation seems to be modulated by solar flux $F_{10.7}$, which presents a weaker variation during low solar activity years. The summer to winter hemispheric asymmetry has also been studied by Su et al. (1998). Using both satellite observations and model calculations, they pointed out that the asymmetry should result from the effects of the transequatorial component of the neutral wind from the summer hemisphere to the winter hemisphere. We tend to accept their interpretations, although the plasma data we are using was obtained $200 \mathrm{~km}$ higher than their observations. The weaker asymmetry of the $\mathrm{Ni}$ distribution at solar minimum should result from its low $\mathrm{O}^{+}$concentration. As shown in Fig. 5, the light ions is predominant between $\pm 60^{\circ}$. Since the scale height of light ions are much 

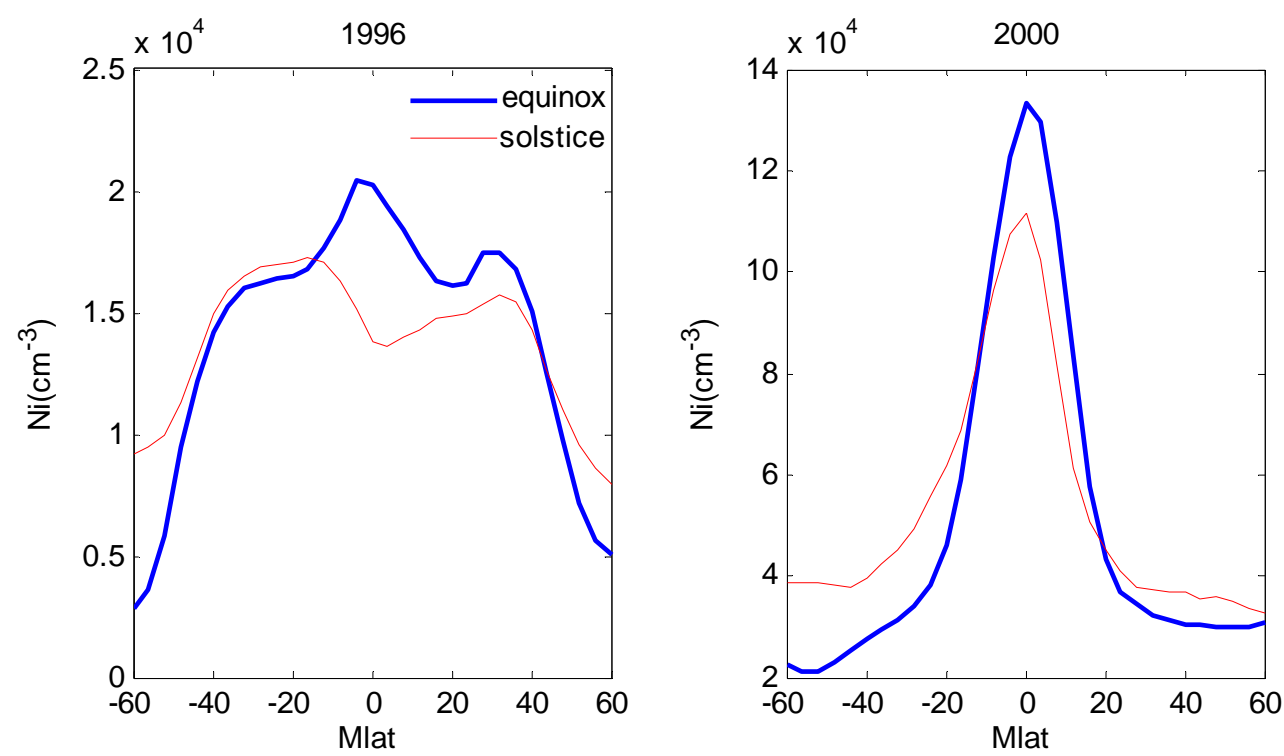

Fig. 6. Comparison between the nighttime average value of two equinox months and two solstice months for solar minimum 1996 and solar maximum 2000.

larger than that of $\mathrm{O}^{+}$, the raising or lowering of the F-layer would produce little change in the plasma density, making asymmetry less pronounced.

The third EOF pattern reflects an enhancement in tropical $\mathrm{Ni}$. However, its associated EOF coefficient at 09:30 LT shows a rather erratic variation. It is hard to give any physical explanation for it. The nighttime coefficient presents a clear semiannual variation, with the equinox value much higher than the solstice value. This may be regarded as the effect of a seasonal dependence of the equatorial $\boldsymbol{E} \times \boldsymbol{B}$ drift. Early incoherent scatter radar and satellite observations showed that the quiet-time F-region vertical drifts in the equatorial region have large seasonal variations during solar maximum and minimum (Fejer, 1981; Fejer et al., 1995). Their results revealed that for Eq. (1) the evening pre-reversal enhancement of the Jicamarca upward drift is almost entirely absent for solar minimum, except during the equinoctial months, for Eq. (2) during moderate to high solar flux and magnetically quiet conditions, the pre-reversal enhancement is most pronounced at equinox, and for Eq. (3) the pre-reversal enhancement of the upward drift increases significantly with solar flux during equinox and summer. The increased F-layer in the equatorial region will therefore enhance the plasma density at a fixed height in the topside ionosphere. Another possible explanation could result from the effect of the wind pattern. At solstice, the overall summer to winter meridional winds will raise the plasma density in the summer hemisphere and reduce it in the winter hemisphere, as is shown in the second EOF. However, the average value of the winter and summer ion densities in one hemisphere at middle to low latitudes is larger than the average value of the densities during the two equinoxes when the meridional wind is weak. The effect is shown in Fig. 6 by comparing the average values of the ion densities for the two solstice months with the two equinox months for solar minimum (1996) and solar maximum (2000), respectively. Figure 6 shows that during both low and high solar activity years, the average value of $\mathrm{Ni}$ during solstices is higher than during equinoxes between low and middle latitudes. Thus, when we remove the mean value, solar cycle, annual and seasonal variations, the residual variation could explain the negative phase in the mid-low latitudes in the third EOF. It should be noted that the latitude distribution of $\mathrm{Ni}$ in 1996 clearly shows double peaks and an equatorial trough. The variation resembles the one observed by Brace et al. (1968) and Reddy et al. (1967) between 00:00-03:00 LT in 1964, which was also a time of low $F_{10.7}$ flux. Fejer (1981) pointed out that the evening reversal time from upward daytime to downward nighttime drifts occurs up to a few hours earlier during solar minimum. Thus, the pre-reversal enhancement would no longer increase the equatorial plasma density at 21:30 LT. However, because of the equinox enhancement, the equatorial plasma keeps increasing, which is consistent with a peak in the equatorial region, as shown in the left panel of Fig. 6.

\section{Further analysis}

We have to make two supplements to the above physical explanations of the EOF coefficients variations. By using Hinotori satellite data, Su et al. (1998) observed that the topside ionosphere at $600 \mathrm{~km}$ has a large annual component: the global average electron density during December solstice is $100 \%$ greater than that during June solstice. Here, we observed the same annual variation but more consideration should be given to the effects of solar flux. Figures $7 \mathrm{a}$, $b$ show latitudinal variation of the observed averaged ion 

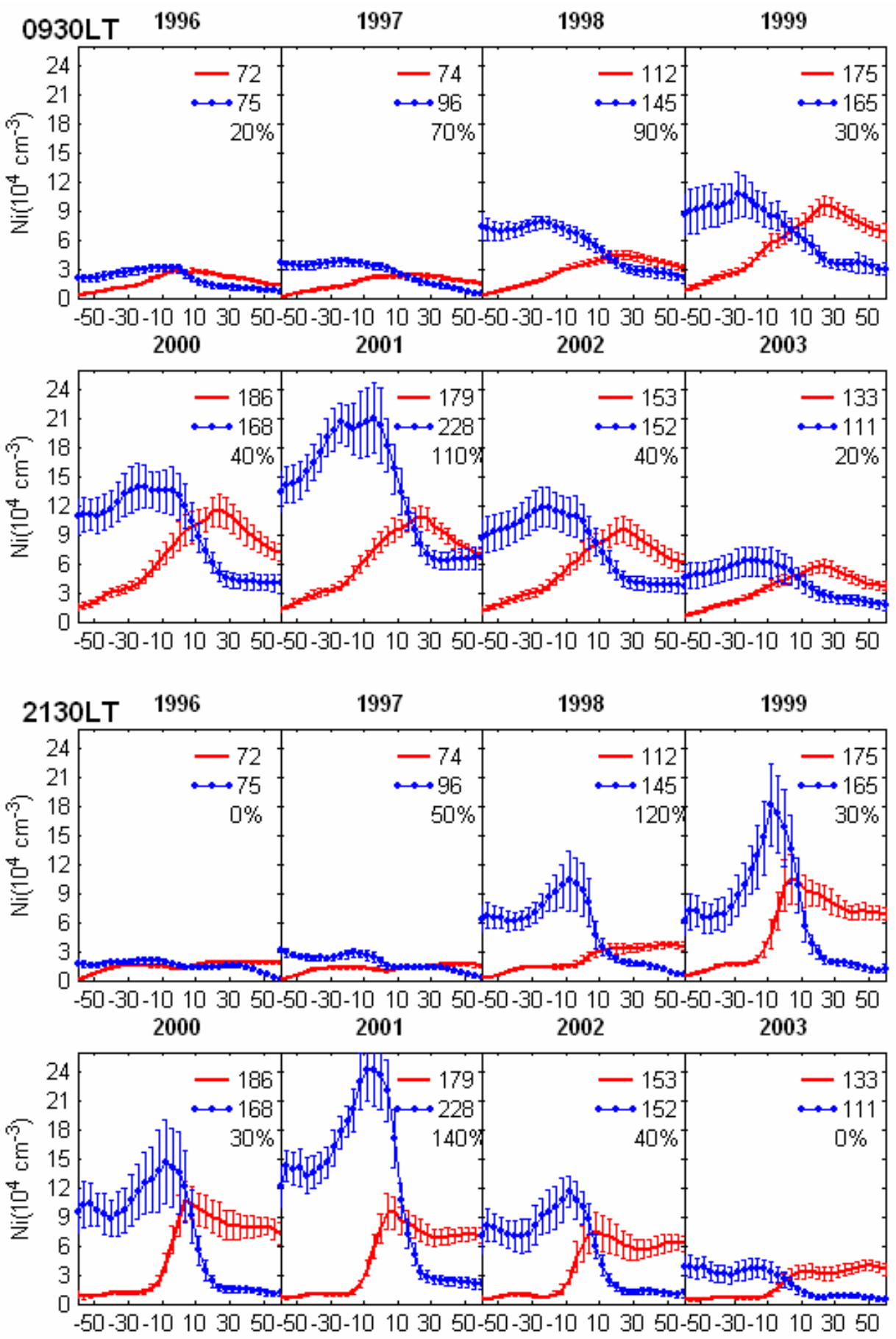

Fig. 7. Latitudinal variations of the average observed electron density during June solstice (solid curves) and December solstice (dotted curves). (A) is for 09:30 LT and (B) for 21:30 LT.

density for the June solstice (solid curves) and the December solstice (dotted curves) at 09:30 LT and 21:30 LT, respectively, for the years 1996-2003. As illustrated in Fig. 7, the ion densities in the Southern Hemisphere are much higher during summer (December solstice) than during winter (June solstice). In the Northern Hemisphere, the ion densities during summer (June solstice) are slightly higher at the higher latitudes. The annual variation is very weak during the low and moderate solar activity years 1996 and 2003, respectively. The ion densities at the conjugate latitudes within the $\pm 60^{\circ}$ latitude range are higher during December solstice than during June solstice by only 20\% at 09:30 LT. At 21:30 LT, there is no difference. The annual variation is obvious for the years 1999, 2000 and 2002. The difference between the December and June values are in the 30-40\% range, when the solar activities are nearly at the same level. The annual 
Table 3. List of fitting coefficients with respect to the Eqs. (3) and (6).

\begin{tabular}{lcccccccccc}
\hline & \multicolumn{1}{c}{ Solar trend } & \multicolumn{4}{c}{ Annual component } & \multicolumn{4}{c}{ Semiannual component } \\
\hline & $C_{0}$ & $c_{0}^{\prime}$ & $C_{1}$ & $c_{1}^{\prime}$ & $S_{1}$ & $S_{1}^{\prime}$ & $c_{2}$ & $c_{2}^{\prime}$ & $S_{2}$ & $S_{2}^{\prime}$ \\
\hline$A_{1(0930)}$ & & & -1.0205 & 0.0135 & -0.1378 & -0.0002 & & & & \\
$A_{1(2130)}$ & & & -1.1187 & 0.0146 & -0.6030 & 0.0051 & & & & \\
\hline \hline$A_{1}$ & -4.4099 & 0.0322 & -0.9300 & 0.0124 & -0.1536 & 0.0016 & 0.0917 & -0.0015 & 0.2694 & -0.0031 \\
$A_{2}$ & -0.7818 & 0.0058 & 0.4195 & -0.0100 & -0.2834 & 0.0039 & 0.1979 & -0.0028 & 0.0908 & -0.0009 \\
$A_{3}$ & -0.1240 & 0.0010 & 0.1229 & -0.0006 & -0.1480 & 0.0015 & 0.0391 & -0.0003 & -0.0959 & 0.0009 \\
\hline
\end{tabular}

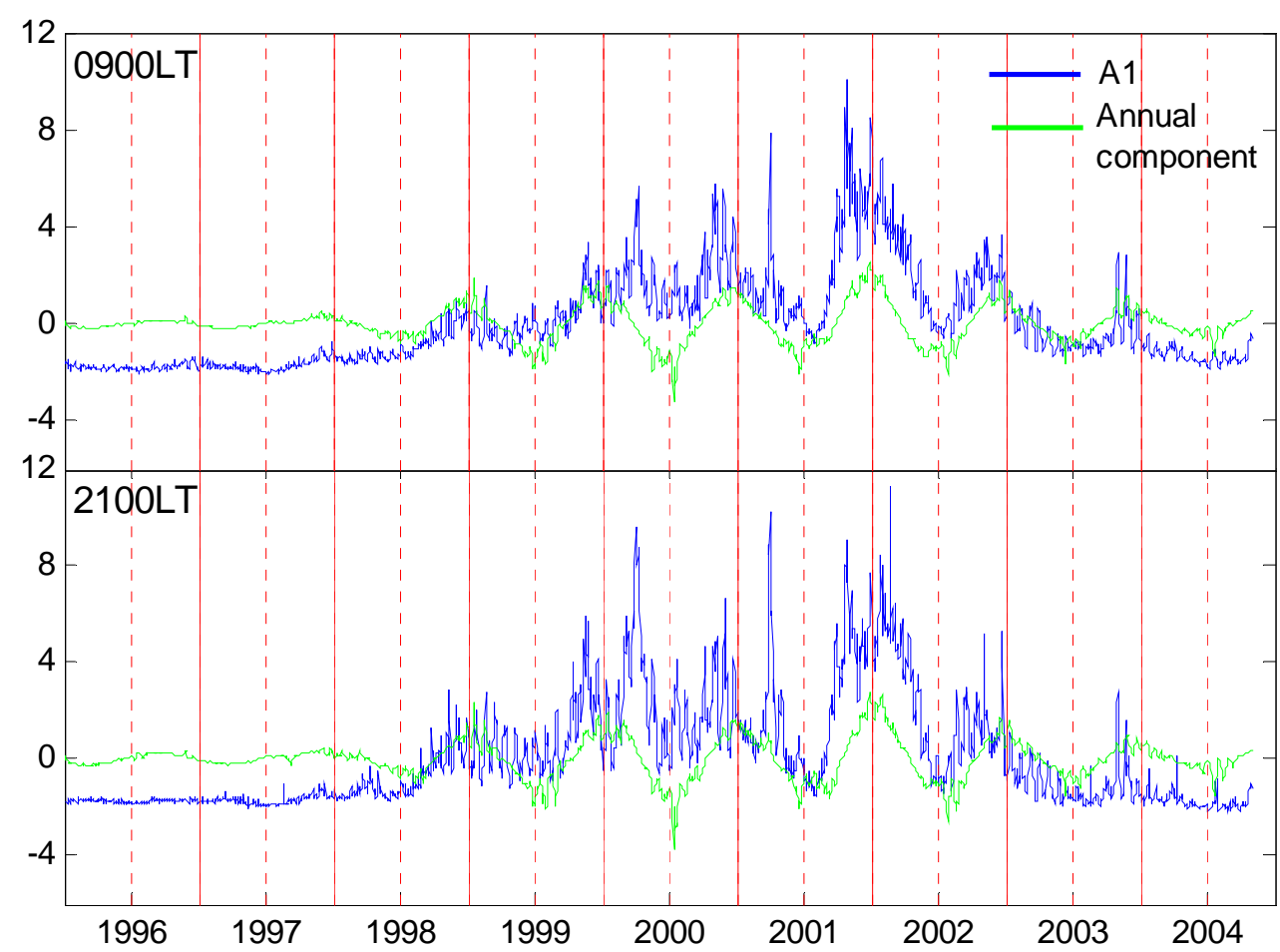

Fig. 8. A1 coefficient and its associated annual component (derived from Eq. 3) for 09:30 LT and 21:30 LT.

variation is significant for the years 1997, 1998 and most notably, the year 2001. However, the contribution from $F_{10.7}$ in December of these three years is, on average, higher by $27 \%$ than in June. The solar flux can account for 1/5 1/4 of the total annual variability for the years 1998 and 2001 but $1 / 3 \sim 1 / 2$ for the year 1997. So the effect of solar EUV flux on the annual variability varies from year to year, but generally the annual variability increases with solar activity. Actually, in our EOF analysis the first EOF component $A_{1}$ contains the annual variation. We have made a fit by using the following function for $A_{1}$ :

$\left(c_{k 1}+c_{k 1}^{\prime} F_{10.7}(d)\right) \cos \frac{2 \pi d}{365}+\left(s_{k 1}+s_{k 1}^{\prime} F_{10.7}(d)\right) \sin \frac{2 \pi d}{365}$.

The values of constants $c_{k 1}, c_{k 1}^{\prime}, s_{k 1}$ and $s_{k 1}^{\prime}$ are listed in the upper panel of Table 3. The function is expressed as two sinusoidal functions with periods of one year which are modulated by a linear function of the $F_{10.7}$ value. Using a least-squares fitting, we obtained the annual variation hidden in $A_{1}$. Figure 8 displays the $A_{1}$ variation and its corresponding fitting curve at 09:30 LT and 21:30 LT. The curves clearly show an increasing annual variation associated with increased solar activity during the period 1998-2003. Our result indicates that the behavior in the topside ionosphere is rather different from that in the F-region. The fact that the annual anomaly is small in the F-region (Torr and Torr, 1973; Yonezawa, 1971) and large in the topside ionosphere suggests that the annual anomaly increases with altitude. This annual variability may just explain why the ion density of the first EOF in the Southern Hemisphere is higher than that in the Northern Hemisphere with respect to the first EOF function. This could be explained by the asymmetry of the geomagnetic field. It has been suggested (Torr and Torr, 1973) that the Southern Hemisphere in winter may receive more energy than the Northern Hemisphere does because the offset between the geographic and magnetic poles is larger 

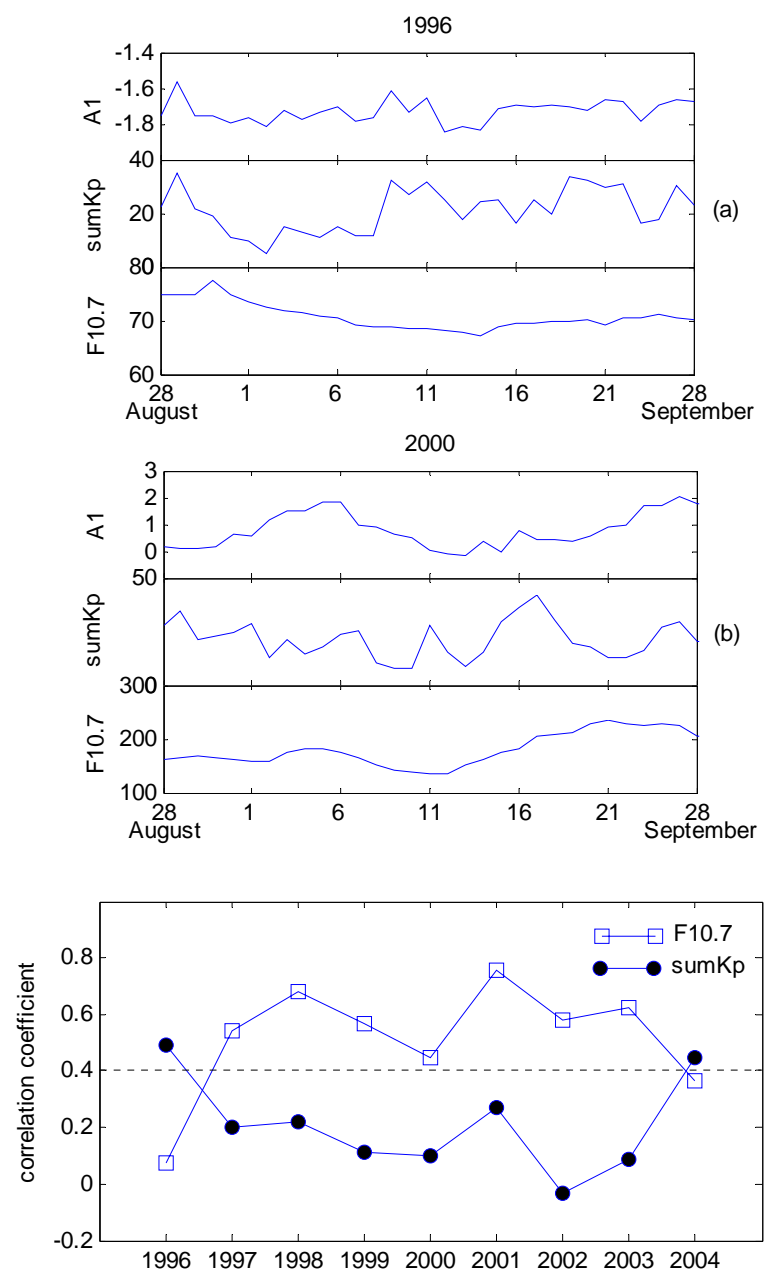

Fig. 9. The variation of $\mathrm{A} 1, \operatorname{sum} K_{p}$ and $F_{10.7}$ during the period 28 August to 28 September in the year 1996 (a), same as (a) but in the year 2000 (b), yearly correlation coefficient between A1 and $F_{10.7}$ (circle) and $\operatorname{sum} K_{p}$ (square) (c).

in the Southern Hemisphere. Since thermospheric circulation transports neutral gases from the summer hemisphere to the winter hemisphere, the asymmetry of the energy input with respect to the equator might give rise to more energy being transported to the equatorial regions from the Southern Hemisphere during the December solstice than from the Northern Hemisphere during the June solstice. For example, if the equatorward component of the winds is stronger during the December solstice than during the June solstice, then the wind could contribute to the annual anomaly in the electron density.

Besides the annual variability, we have to consider the effects of geomagnetic disturbances. Past studies have shown that the topside ionosphere is very sensitive to magnetic disturbances. Generally, there are three ways in which the topside plasma density distribution can severely change in the middle, low and equatorial regions. One is the enhanced storm-time neutral wind system which can raise the $F_{2}$ layer peak and increase the plasma density at higher altitudes
(Reddy et al., 1967; Kil et al., 2003). The second is the enriched molecular gases, being produced in the auroral oval due to particle precipitation and Joule heating, which are carried by storm-enhanced meridional wind to the middle latitudes and decrease the local plasma density there (Kil et al., 2003). The third factor is the electrodynamics that seems to satisfactorily account for the storm-time behavior of the equatorial region. Blanc and Richmond (1980) showed that the zonal component of wind disturbance electric fields is westward during the day and eastward at night, resulting in downward and upward equatorial F-region plasma drifts. These drifts may be responsible for the nighttime enhancement and daytime depression in plasma density at the equator (Reddy et al., 1967). Sometimes the equatorial topside ionosphere can undergo a drastic depletion at 21:30 LT when a very intense magnetic storm occurs (e.g. Greenspan et al., 1991; Basu et al., 2001; Lee et al., 2002; Foster et al., 2002). Such situations are rarer during small and moderate magnetic storms. So an increase in $N i$ is seen more often at middle and low latitudes in both hemispheres. Hence, its contribution to the first EOF should not be neglected.

We select an interval that spans from 28 August to 28 September for the solar minimum 1996 and solar maximum 2000, and plot the $F_{10.7}, \operatorname{sum} K_{p}$ (the sum of the planetary 3-h $K_{p}$ indices for a day), and nighttime first principal component $A_{1}$ during these periods. As shown in Fig. 9a, the $A_{1}$ from 28 August to 11 September 1996 varies in phase with those of $\operatorname{sum} K_{p}$. There is no evidence of a relationship between $A_{1}$ and $F_{10.7}$. As a matter of fact, the discussion of the storm-time response of the topside ionosphere should be more specifically restrained to case studies. We have examined storm effects for more than a hundred cases during 1996-2004 and found that the storm characteristics of the topside ionosphere depend greatly on the phase development of the magnetic storm. It is often seen that $N i$ is enhanced during the main phase of the storm $\left(D_{s t}\right.$ minimum) and depressed during the recovery phase ( $D_{s t}$ returns to zero). The daily average value for $N i$ and $K_{p}$ may smooth out these processes. It can be seen in Fig. 9a that $A_{1}$ drops quickly and stays low on 11 August, which might be related to the magnetic disturbance on that day. The situation is the opposite during solar maximum. As is displayed in Fig. 9b, the trend is that $A_{1}$ is positively correlated with the $F_{10.7}$ variation. There is no obvious peak-to-peak relationship between $A_{1}$ and $\operatorname{sum} K_{p}$. It seems like the magnetic effect on the distribution of the topside ionosphere is more significant during solar minimum. We have calculated the yearly correlation coefficient between $A_{1}$ and $F_{10.7}, A_{1}$ and $\operatorname{sum} K_{p}$. The result that we plot in Fig. 9c shows that the magnetic disturbance is negatively correlated with the solar flux variation. If we take 0.4 as a level that signifies a reasonable confidence of meaningful correlation, then the magnetic effect can only be important in the years 1996 and 2004. Since the topside ionosphere is largely controlled by the solar flux, the increased solar activity will make the effect of magnetic disturbance less evident. As a matter of fact, there are many cases in which the $F_{10.7}$ and $\operatorname{sum} K_{p}$ are coupled and well 
correlated with the $A_{1}$ in a specific month. However, with respect to the long term, we can ignore the effects of $\operatorname{sum} K_{p}$, and this is convenient for us to setup an empirical model for a long-term prediction.

\section{Empirical model}

Since the first three EOFs are able to explain more than $95 \%$ of DMSP data set variance, we only need these EOFs to reconstruct the whole picture of the original data set. Equation (1) is simplified to

$$
\begin{aligned}
& N i(d, m)= \\
& \overline{N i}(m)+A_{1}(\text { solar }) \times E_{1}+A_{2}(\text { asym }) \times E_{2}+A_{3}(\text { sym }) \times E_{3}
\end{aligned}
$$

As discussed above, the first three EOF coefficients, $A_{1}, A_{2}$ and $A_{3}$, each manifests chiefly the solar cycle, annual (north to south) and semiannual variations, respectively. Thus we generally separate $A_{k}(k=1,2,3)$ into three parts, $A_{k}^{(0)}, A_{k}^{(1)}$ and $A_{k}^{(2)}$, to represent, respectively, the corresponding variations,

$A_{k}(d)=A_{k}^{(0)}(d)+A_{k}^{(1)}(d)+A_{k}^{(2)}(d)+$ error .

The solar cycle variation $A_{k}^{(0)}$, as well as the amplitudes of the annual variation $A_{k}^{(1)}$ and semiannual variation $A_{k}^{(2)}$, depends strongly on the solar activity index $F_{10.7}$. Therefore, we express each of $A_{k}^{(0)}, A_{k}^{(1)}$ and $A_{k}^{(2)}$ with an analytical model,

$$
\begin{aligned}
& A_{k}^{(0)}(d)=c_{k 0}+c_{k 0}^{\prime} F_{10.7}(d) \\
& A_{k}^{(1)}(d)=\left(c_{k 1}+c_{k 1}^{\prime} F_{10.7}(d)\right) \cos \frac{2 \pi d}{Y}+\left(s_{k 1}+s_{k 1}^{\prime} F_{10.7}(d)\right) \sin \frac{2 \pi d}{Y} \\
& A_{k}^{(2)}(d)=\left(c_{k 2}+c_{k 2}^{\prime} F_{10.7}(d)\right) \cos \frac{2 \pi d}{Y / 2}+\left(s_{k 2}+s_{k 2}^{\prime} F_{10.7}(d)\right) \sin \frac{4 \pi d}{Y / 2} .
\end{aligned}
$$

In Eq. (6), the solar cycle variation $A_{k}^{(0)}$ is expressed as linear functions of $F_{10.7}$, and the annual and semiannual variation $A_{k}^{(1)}$ and $A_{k}^{(2)}$ are expressed as modulated sinusoidal functions with periods of one year $(Y=365)$ and half a year $(Y / 2)$, respectively. The modulations of the sinusoidal functions are also fitted as linear functions of $F_{10.7}$. Thus, Eqs. (5) and (6) express the EOF coefficients $A_{k}(d)$ as formalizing Fourier series. In such series the zero, first and second order terms represent, respectively, the solar cycle, annual and semiannual variations; the coefficients of the series are designed as linear functions of $F_{10.7}$. Thus, by a linear regression method, the coefficients in Eq. (6), $c_{k l}$ and $c_{k l}^{\prime}(k=1,2,3, l=0,1,2)$ and $s_{k l}$ and $s_{k l}^{\prime}(k=1,2,3, l=0,1,2)$ are first computed and then used to determine $A_{k}^{(l)}(d)(k=1,2,3, l=0,1,2)$. The determined $A_{k}(l)(d)$ are further used to model the EOF coefficients $A_{k}(d)$. Finally, putting the modeled $A_{k}(d)$ into Eq. (4), we construct a statistical model.

We use the 8-year data set that covers the period 19962003 to construct the model, and test the model by using the data of 2004. Take 09:30 LT for example, where the original EOF coefficients $A_{k}(d)$ of year 1996-2003 (red line), modeled EOF coefficients $A_{k}(d)$ of years 1996-2003 (green) and the original EOF coefficients $A_{k}(d)$ of years 1996-2004 (blue) are plotted in Fig. 10. The set of constants for each order are listed in the lower panel of Table 3. Comparing with the original EOF coefficients, we find that the modeled EOF coefficients coincide well with the original. Applying day number $d$ and $F_{10.7}$ as input parameters, we calculate the value for the year 2004. The predicted $N i$ for the year 2004 is compared with the observed $N i$ in Fig. 11a. It is obvious that the modeled $N i$ can well reproduce the 27-day solar cycle, annual and semiannual variations of the original data set. The percentage variance $\operatorname{var}\left(\left(N i_{\text {mod }}-N i_{\text {obs }}\right) /\left(N i_{\text {obs }}\right) \times 100 \%\right)$ of the model is 0.057 . The percentage error is shown to present a normal distribution. The modeled $N i$ is shown to be a little higher than the observed one with a relative deviation of 0.2503 . The reason should be due to the fact that the modeled EOF coefficients are predicted larger than the original EOF coefficients in the year 2004, as shown in Fig. 10.

As mentioned in Sect. 4, the solar flux's control of the topside ionosphere decreases with decreasing solar activity. So we expect the model to be better for a higher solar activity year. Figure $11 \mathrm{~b}$ gives the modeled and observed $\mathrm{Ni}$ for the year 2003. The reconstruction coefficients are derived from the data during 1996-2002. The percentage variance is 0.0740 and relative deviation is 0.1129 . The percentage variance should be closer to that in 2004 because 2004 has only ten months of data. The relative deviation has been reduced by $50 \%$. The percentage error also shows a normal distribution. It is expected that the modeled $N i$ for nighttime is worse than during the daytime because the first EOF coefficient $A_{1}(d)$ has a lower correlation to solar flux than during the daytime.

Figure 11c illustrates the comparison of modeled and observed $N i$ at 21:30 LT in the year 2003. The percentage variance is 0.2634 and relative deviation is 0.7586 . Even so, the modeled $N i$ clearly shows 27 -day, annual and seasonal variations which are very similar to the observed values. Though the percentage variance is a little bigger, the distribution is normal.

Our results reveal that the modeled $N i$ derived from the EOF expansion is capable of capturing the maximum amount of the characteristics of the original data set. However, the prediction ability depends largely on the first EOF coefficient, which contributes to the most variance. Since the correlation coefficients between the solar flux and the first EOF coefficient decrease with decreasing solar activity, it would be better to model separately during solar maximum and minimum. The model is good for prediction at solar maximum. At solar minimum, we should consider other factors, for example, the effect of the magnetic disturbances. So a more comprehensive model is needed for a more accurate prediction. 


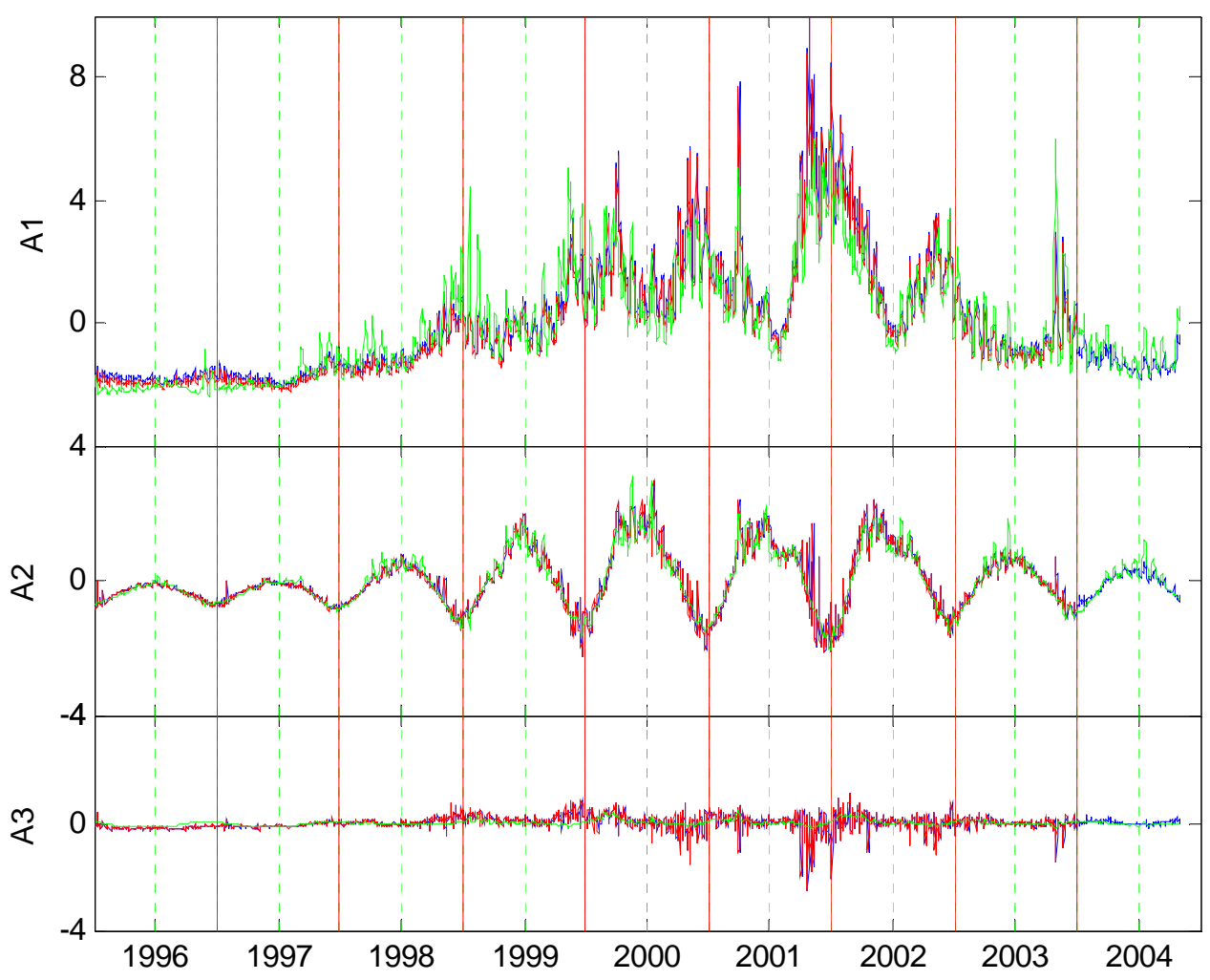

Fig. 10. The red line represents the first EOF coefficient A1 that is derived from the 1996-2003 data set. The blue line denotes A1 that is derived from the 1996-2004 data set. The green line indicates the modeled A1 using the A1 from 1996-2003.

\section{Discussion and conclusion}

The EOF method is introduced to analyze and model the topside ionosphere's plasma density $N i$ at middle to equatorial latitudes. The 9-year DMSP Ni data at 09:30 LT and 21:30 LT was, respectively, decomposed into a time mean plus the sum of orthogonal functions of space multiplied by time-varying coefficients. We have found that the total covariance contribution of the first three components is able to explain more than $95 \%$ of the whole data set variance. Both the latitude distribution and temporal variation are discussed with respect to the first three EOFs $E$ and their associated coefficients $A$, in decreasing order of importance. Our results have shown that at both the morning side and post-sunset sectors, the $N i$ variation is highly correlated with the solar flux $F_{10.7}$. The summer to winter annual variability has a close relationship with the solar declination. We propose that an interhemispheric wind should play a major role in causing this asymmetry. The third EOF that describes the north to south symmetry seems hard to explain by the current theory at 09:30 LT. However, it represents a clear semiannual variation at 21:30 LT which may be interpreted as the effect of a seasonal variation of the post-sunset, pre-reversal enhancement. Furthermore, all these variabilities are obviously modulated by solar activity.

In addition, the winter anomaly variability, which is observed by Su et al. (1998), was discussed in association with the solar $F_{10.7}$ flux. Our result shows that the winter anomaly increases with increasing solar activity level. In addition, the magnetic index $\operatorname{sum} K_{p}$ is better correlated with the first EOF coefficient during solar minimum. The EOFs are ordered by the amount of variance they capture from the original data set. However, this will not guarantee that the modes of variability identified by the EOFs are associated with actual physical processes. The winter anomaly and magnetic disturbances are both coupled in the first EOFs. But this will not affect our long-term (nearly a solar cycle) model construction. For each of the coefficients, we have used a formalized Fourier series with a base period of a year and an amplitude which is a linear function of the solar activity index, $F_{10.7}$, to construct our model. The predicted results present a clear 27-day variation, as well as a summer to winter annual variability and semiannual variation. Through error analysis, we see that the prediction is better for the daytime during high solar activity years. It suggests that ionospheric characteristics of the topside ionosphere originate with the solar flux and are also modified by the wind and electrodynamics. Since plasma density is mainly composed of $\mathrm{O}^{+}$during moderate and high solar activity, many of its variation can be linked to the changing of the $\mathrm{F}_{2}$-layer. However, the mechanism that drives the morphology of the $N i$ distribution in the topside seems to be simpler than that affecting the $\mathrm{F}_{2}$ layer which is more molecular (Zou et al., 2000; Rishbeth et al., 2000). This reconstruction method may be used to recuperate or rectify a 

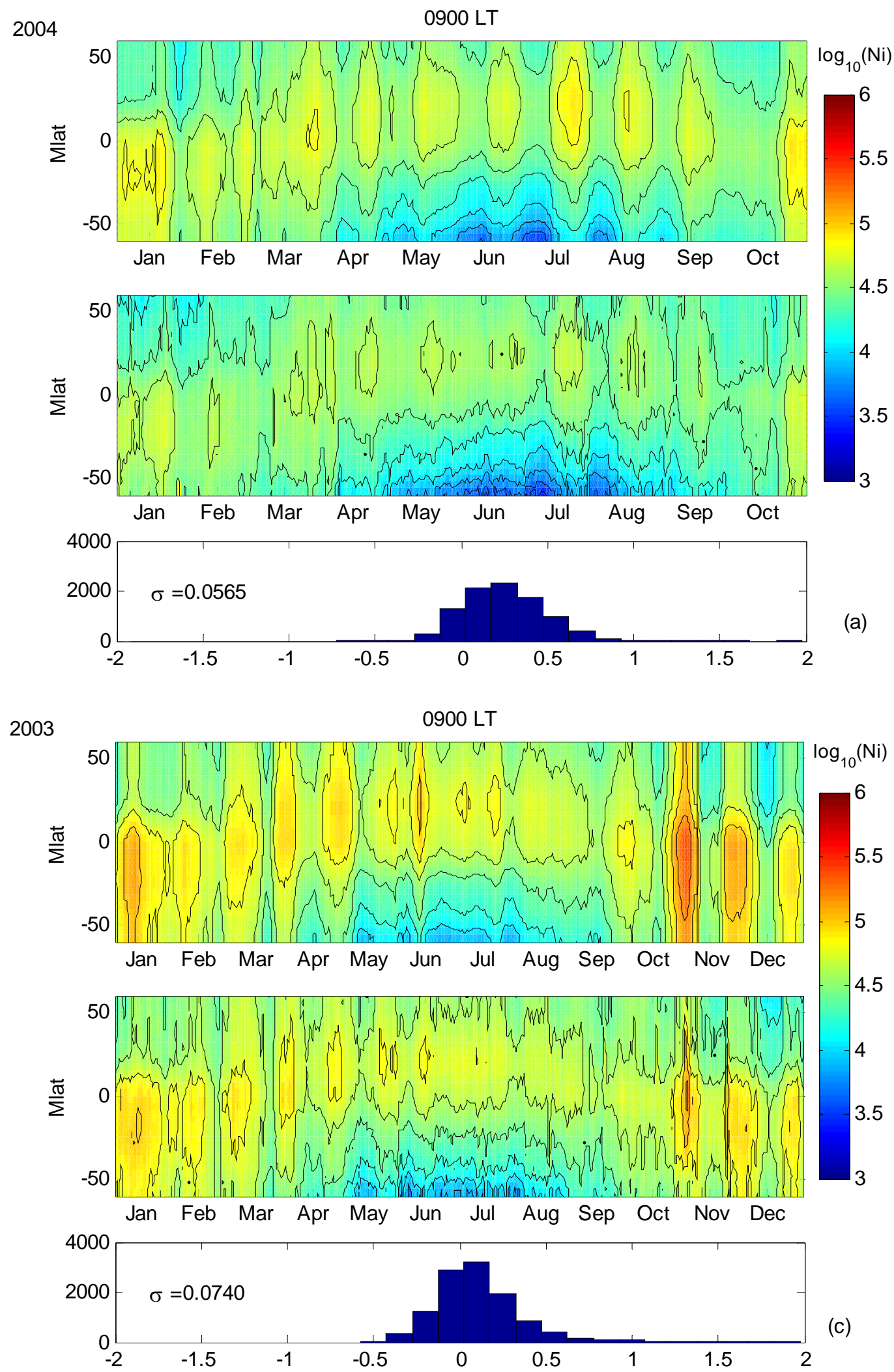

Fig. 11. Comparison between the predicted and observed $N i$ for the year 2004 at 09:30 LT (a), year 2003 at 09:30 LT (b), year 2003 at 21:30 LT (c). The bottom panel of each figure represents the histogram of the percentage error. 


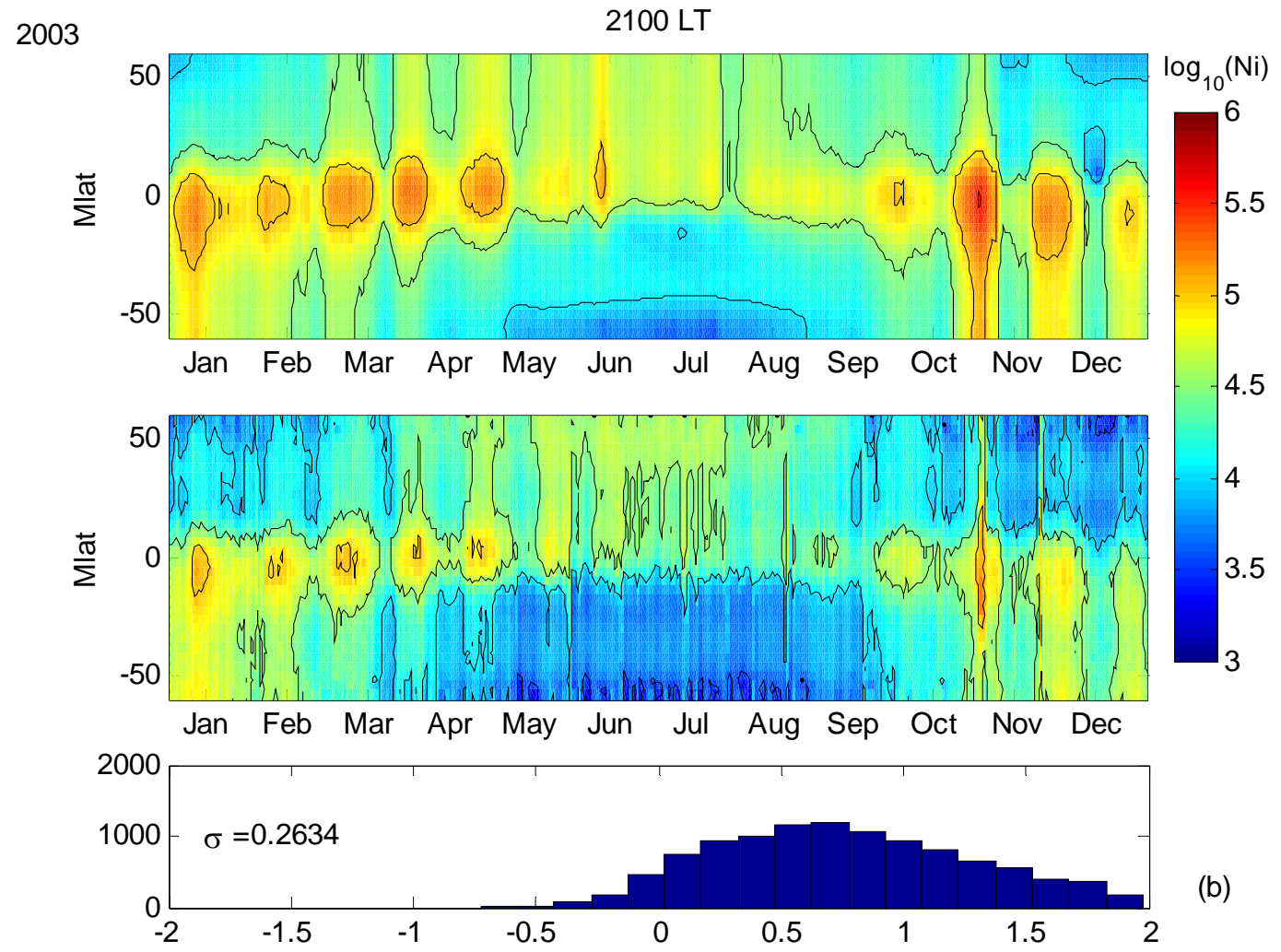

Fig. 11. Continued.

long-term data set which has a large data gap for some reason, such as the failure of the normal operation of an instrument.

We haven't discussed the longitudinal effects on the distribution of $N i$ in this paper, which will surely introduce some extra physical processes. The plasma density at high latitudes and in the polar region should also be considered. Further work is thus needed to separate data into different longitudes and to concentrate on the polar region, as well as to examine how various processes affect the topside ionosphere in a solar cycle.

Acknowledgements. This work is supported by the KIP Pilot Project (kzcx3-sw-144) of CAS, National Science Foundation of China (40134020), and National Important Basic Research Project (G2000078407). The authors also express their special thanks to the Center for Space Sciences at University of Texas at Dallas and the US Air Force for providing the DMSP thermal plasma data.

Topical Editor M. Pinnock thanks G. Millward and F. J. Rich for their help in evaluating this paper.

\section{References}

Bailey, G. J., Su, Y. Z., and Oyama, K. -I.: Yearly variations in the low-latitude top ionosphere, Ann. Geophys., 18, 789-798, 2000, SRef-ID: 1432-0576/ag/2000-18-789.

Balan, N., Otsuka, Y., Bailey, G. J., Fukao, S., and Abdu, M. A.: Annual variations of the ionosphere: A review based on the MU radar observations, Adv. Space Res., 25, 153-162, 2000.
Balan, N., Otsuka, Y., Bailey, G. J., and Fukao, S.: Equinoctial asymmetries in the ionosphere and thermosphere observed by the MU radar, J. Geophys. Res., 103, 9481-9495, 1998.

Basu, S., Basu, Su., Groves, K. M., Yeh, H. -C., Su, S. -Y., Rich, F. J., Sultan, P. J., and Keskinen, M. J.: Response of the equatorial ionosphere in the South Atlantic region to the great magnetic storm of July 15, Geophys. Res. Lett., 2000, 28, 3577-3580, 2001.

Blanc, M. and Richmond, A. D.: The ionospheric disturbance dynamo, J. Geophys. Res., 85, 1669-1686, 1980.

Brace, L. H., Reddy, B. M., and Maya, H. G.: Global Behavior of the ionosphere at 1000-kilometer altitude, J. Geophys. Res., 72, 265-283, 1967.

Brace, L. H., Maya, H. G., and Reddy, B. M.: The early effects of increasing solar activity upon the temperature and density of the 1000-kilometer ionosphere, J. Geophys. Res., 73, 1607-1615, 1968.

Chandra, S. and Rangaswamy, S.: Geomagnetic and solar control of ionization at $1000 \mathrm{~km}$, J. Atmos. Terr. Phys., 29, 259-265, 1967.

Chen, Y., Wan, W., Liu, L., and Li, L.: A statistical TEC model based on the observation at Wuhan Ionopheric Observatory, Chinese J. Space Sci., 22, 27-35, 2002.

Daniell, R. E., Brown, L. D., Anderson, D. N., Fox, M. W., Doherty, P. H., Decker, D. T., Sojka, J. J., and Schunk, R. W.: Parameterized ionospheric model: a global ionospheric parameterization based on first principles models, Radio Sci., 30, 1499-1510, 1995.

Fejer, B. G.: The equatorial ionospheric electric fields: A review, J. Atmos. Terr. Phys., 43, 377-386, 1981.

Fejer, B. G.: Low latitude electrodynamic plasma drifts: A review, 
J. Atmos. Terr. Phys., 53, 677-693, 1991.

Fejer, B. G., Paula, E. R., Heelis, R. A., and Hanson, W. B.: Global equatorial ionospheric vertical plasma drifts measured by the AE-E satellite, J. Geophys. Res., 100, 5769-5776, 1995.

Fejer, B. G., Scherliess, L., and Paula, E. R.: Effects of the vertical plasma drift velocity on the generation and evolution of equatorial spread F, J. Geophys. Res., 104, A9, 19 859-19869, 1999.

Foster, J. C., Coster, A. J., Goldstein, J., and Rich, F. J.: Ionospheric signatures of plasma tails, Geophys. Res. Letters, 29, 13, doi:10.1029/2002GL015067, 2002.

González, S. A., Fejer, B. G., Heelis, R. A., and Hanson, W. B.: Ion composition of the topside equatorial ionosphere during solar minimum, J. Geophys. Res., 97, 4299-4303, 1992.

González, S. A., Sulzer, M. P., Nicolls, M. J., and Kerr, R. B.: Solar cycle variability of nighttime topside helium ion concentrations over Arecibo, J. Geophys. Res., 109, A07302, doi:10.1029/2003JA010100, 2004.

Greenspan, M. E., Rasmussen, C. E., Burke, W. J., and Abdu, M. A.: Equatorial density depletions observed at $840 \mathrm{~km}$ during the great magnetic storm of March 1989, J. Geophys. Res., 96, 13 931-13 942, 1991.

Greenspan, M. E., Burke, W. J., Rich, F. J. Hughes, W. J., and Heelis, R. A.: DMSP F8 observations of the mid-latitude and low-latitude top ionosphere near solar minimum, J. Geophys. Res., 99, 3817-3826, 1994.

Hanson, W. B.: Electron temperatures in the upper atmosphere, Space Res., 3, 282-302, 1963.

Heelis, R. A., Bailey, G. J., and Hanson, W. B.: Ion temperature troughs and interhemispheric transport observed in the equatorial ionosphere, J. Geophys. Res., 83, 3683-3689, 1978.

Heelis, R. A., and Hanson W. B.: Interhemispheric transport induced by neutral zonal winds in the F-region, J. Geophys. Res., 85, 3045-3047, 1980.

Heelis, R. A., Hanson W. B., and Bailey, G. J.: Distributions of the $\mathrm{He}^{+}$at middle and equatorial latitudes during solar maximum, $\mathrm{J}$. Geophys. Res., 95, 10313-10320, 1990.

Kil, H., Paxton, L. J., Pi, X., Hairston, M. R., and Zhang, Y.: Case study of the 15 July 2000 magnetic storm effects on the ionosphere-driver of the positive ionospheric storm in the winter hemisphere, J. Geophys. Res., 108(A11), 1391, doi:10.1029/2002JA009782, 2003.

Kutiev, I., Heelis, R. A., and Sanatani, S.: The behavior of the $\mathrm{O}^{+}$$\mathrm{H}^{+}$Transition level at solar maximum, J. Geophys. Res., 85, 2366-2372, 1980.

Lee, J. J., Min, K. W., Kim, V. P., Hegai, V. V., Oyama, K. -I., Rich, F. J., and Kim, J.: Large density depletions in the nighttime upper ionosphere during the magnetic storm of July 15, 2000, Geophys. Res. Lett., 29(3), doi:10.1029/2001GL013991, 2002.

Ma, R., Xu, J., and L., H.: The features and a possible mechanism of semiannual variation in the peak electron density of the low latitude $\mathrm{F}_{2}$ layer, J. Atmos. and Solar-Terr. Phys., 65, 47-57, 2003.

MacPherson, B., Gonzalez, S. A., Bailey, G. J., Moffett, R. J., and Sulzer, M. P.: The effects of meridional winds on the $\mathrm{O}^{+}-\mathrm{H}^{+}$ transition altitude over Arecibo, J. Geophys. Res., 103, 29 18329 198, 1998.

Mayr, H. G., Brace, L. H., and Dunham, G. S.: Ion composition and temperature in the top ionosphere. J. Geophys. Res., 72, 43914404, 1967.

Mikhailov, A. V., Leschinskaya, T. Y., Förster, M.: Morphology of NmF2 nighttime increases in the Eurasian sector, Ann. Geophys., 18, 1422-1434, 2000,
SRef-ID: 1432-0576/ag/2000-18-1422.

Millward, G. H., Rishbeth, H., Fuller-Rowell, T. J., Aylward, A. D., Quegan, S., and Moffett, R. J.: Ionospheric $\mathrm{F}_{2}$ layer seasonal and semi-annual variations, J. Geophys. Res., 101, 5149-5156, 1996.

Miyazaki, S.: Ion transition height distribution obtained with the satellite Taiyo, J. Geomagn. Geoelec., 31, 113-124, 1979.

Moffett, R. J. and Hanson, W. B.: Calculated distributions of hydrogen and helium ions in the low latitude ionosphere, J. Atmos. Terr. Phys., 35, 207-222, 1973.

Murphy, J. A., Sutton, A. E., and Heelis, R. A.: The influence of neutral winds on $\mathrm{He}^{+}$distributions in the equatorial ionosphere, Planet. Space Sci., 32, 543-550, 1984.

Reddy, B. M., Brace, L. H., and Findlay, J. A.: The ionosphere at 640 kilometers on quiet and disturbed days, J. Geophys. Res., 72, 2709-2727, 1967.

Rich, F. J.: Technical description for the topside ionospheric plasma monitor (SSIES, SSIES-2 and SSIES-3) on spacecraft of the Defense Meteorological Satellite Program (DMSP), Tech. Rep. PLTR-94-2187, Air Force Phillips Lab., Bedford, Mass., 69, 1994.

Rich, F. J. and Hairston, M.: Large-scale convection patterns observed by DMSP, J. Geophys. Res., 99(A3), 3827-3844, 1994.

Rich, F. J., Sultan, P. J., and Burke, W. J.: The 27-day variations of plasma densities and temperatures in the topside onosphere, J. Geophys. Res., 108(A7), 1297, doi:10.1029/2002JA009731, 2003.

Rishbeth, H., Muller-Wodarg, I. C. F., Zou, L., Fuller-Rowell, T. J., Millward, G. H., Moffett, R. J., Idenden, D. W., and Aylwardm, A. D.: Annual and semiannual variations in the ionospheric $\mathrm{F}_{2}$-layer: II. Physical discussion, Ann. Geophys., 18, 945-956, 2000,

SRef-ID: 1432-0576/ag/2000-18-945.

Storch, H. V. and Zwiers, F. W.: Statistical analysis in climate research, Cambridge University Press, 2002.

Su, Y. Z., Bailey, G. J., and Oyama, K.-I.: Annual and seasonal variations in the low-latitude topside ionosphere, Ann. Geophys., 16, 974-985, 1998,

SRef-ID: 1432-0576/ag/1998-16-974.

Taylor, H. A., Maya, H. G., and Brinton, H. C.: Observations of hydrogen and helium ions during a period of rising solar activity, Space Res., 10, 663-678, 1970.

Titheridge, J. E.: Ion transition heights from topside electron density profiles, Planet. Space Sci., 24, 229-245, 1976.

Titheridge, J. E. and Buonsanto, M. J.: Annual variations in the electron content and height of the F-layer in the northern and southern hemispheres, related to neutral composition, J. Atmos. Terr. Phys., 45, 683-696, 1983.

Torr, M. R. and Torr, D. G.: The seasonal behavior of the $\mathrm{F}_{2}$-layer of the ionosphere, J. Atmos. Terr. Phys., 35, 2237-2251, 1973.

Unnikrishnan, K., Nair, R. B., and Venugopal, C.: Harmonic analysis and an empirical model for TEC over Palehua, J. Atmos. and Solar-Terr. Phys., 64, 1833-1840, 2002.

Venkatraman, S. and Heelis, R. A.: Longitudinal and seasonal variations in nighttime plasma temperatures in the equatorial topside ionosphere during solar maximum, J. Geophys. Res., 104, $2603-$ 2611, 1999a.

Venkatraman, S. and Heelis, R. A.: Effects of solar activity variations on adiabatic heating and cooling effects in the nighttime equatorial topside ionosphere, J. Geophys. Res., 104, $17117-$ $17126,1999 \mathrm{~b}$.

Venkatraman, S. and Heelis, R. A.: Interhemispheric plasma flows in the equatorial topside ionosphere, J. Geophys. Res., 105, 18 457-18 464, 2000. 
Watt, T. M.: Ion distribution and temperature in the top ionosphere obtained from the Alouette satellite, J. Geophys. Res., 70, 58495859, 1965.

West, K. H. and Heelis, R. A.: Longitude variations in ion composition in the morning and evening topside equatorial ionosphere near solar minimum, J. Geophys. Res., 101, 7951-7960, 1996.

West, K. H., Heelis, R. A., and Rich, F. J.: Solar activity variations in the composition of low-latitude topside ionosphere, J. Geophys. Res., 102, 295-305, 1997.

$\mathrm{Xu}, \mathrm{W}$.-Y. and Kamide, Y.: Decomposition of daily geomagnetic variations by using method of natural orthogonal component, J. Geophys. Res., 109, A05218, doi:10.1029/2003JA010216, 2004.
Yonezawa, T.: The solar-activity and latitudinal characteristics of the seasonal, non-seasonal and semi-annual variations in the peak electron densities of the $\mathrm{F}_{2}$-layer at noon and midnight in the middle and low latitudes, J. Atmos. Terr. Phys., 33, 889-907, 1971.

Yu, T., Wan, W., Liu, L., and Zhao, B.: Global scale annual and semi-annual variations of daytime $N m \mathrm{~F} 2$ in the high solar activity years, J. Atmos. and Solar-Terr. Phys., 66, 1691-1701, 2004.

Zou, L., Rishbeth, H., Muller-Wodarg, I. C. F., Aylward, A. D., Millward, G. H., Fuller-Rowell, T. J., Idenden, and D. W., and Moffett, R. J.: Annual and semiannual variations in the ionospheric F $F_{2}$-layer: I. Modelling, Ann. Geophys., 18, 927-944, 2000 ,

SRef-ID: 1432-0576/ag/2000-18-927. 